\title{
The sunspot cycle, the QBO, and the total ozone over Northeastern Europe: a connection through the dynamics of stratospheric circulation
}

\author{
B. Soukharev \\ Department of Climatology, St.-Petersburg State University, 10 linia, 33, St.-Petersburg, 199178, Russia \\ E-mail: BORIS@SEB.USR.PU.RU
}

Received: 13 December 1996 / Revised: 2 June 1997 / Accepted: 17 June 1997

\begin{abstract}
The interaction between the factors of the quasi-biennial oscillation (QBO) and the 11-year solar cycle is considered as an separate factor influencing the interannual January-March variations of total ozone over Northeastern Europe. Linear correlation analysis and the running correlation method are used to examine possible connections between ozone and solar activity at simultaneous moment the QBO phase. Statistically significant correlations between the variations of total ozone in February and, partially, in March, and the sunspot numbers during the different phases of QBO are found. The running correlation method between the ozone and the equatorial zonal wind demonstrates a clear modulation of 11-y solar signal for February and March. Modulation is clearer if the QBO phases are defined at the level of $50 \mathrm{hPa}$ rather than at $30 \mathrm{hPa}$. The same statistical analyses are conducted also for possible connections between the index of stratospheric circulation $C_{1}$ and sunspot numbers considering the QBO phase. Statistically significant connections are found for February. The running correlations between the index $C_{1}$ and the equatorial zonal wind show the clear modulation of 11-y solar signal for February and March. Based on the obtained correlations between the interannual variations of ozone and index $C_{1}$, it may be concluded that a connection between solar cycle QBO - ozone occurs through the dynamics of stratospheric circulation.
\end{abstract}

\section{Introduction}

It is well known that the quasi-biennial oscillation (QBO) of zonal winds in the equatorial stratosphere has an influence on the variability of many meteorological parameters in the stratosphere and troposphere (Holton and Tan, 1980, 1982; Labitzke, 1982; Wallace and Chang, 1982; Tarasenko, 1988; Holton and Austin,
1991; Dunkerton and Baldwin, 1991; Fedorov et al., 1994; Holton, 1994). However, the relation between the equatorial QBO and the variations of meteorological parameters, as a rule, shows only a tendency and not an obvious connection. However, Labitzke and van Loon (1992) have established that the northern winter stratospheric polar vortex is colder during the westerly $(W)$ phases than during the easterly $(E)$ phases of QBO only in $64 \%$ of winters.

Many researchers (Angell, 1988; Stolarsky et al., 1991; Aleksandrov et al., 1992; Karol et al., 1992; Khrgian, 1992; Bekorukov et al., 1994) have studied a possible connection between the QBO and interannual variations of ozone. They have showed that, on average, at the $E$ phase of QBO the ozone concentration in the polar latitudes is higher than at the $W$ phase. According to these authors, the influence of the QBO influences total ozone variations by $1-2 \%$.

Some researchers (Kondratiyev, 1990; Stolarsky et al., 1991; Chandra and McPeters, 1994) have tried to connect the observed interannual anomalies of ozone with solar activity. It was found that the ozone variations caused by the $11-y$ solar cycle are within the limits of $1-3 \%$. According to the WMO Ozone Assessment (1994), the global average total ozone changes are correlated with solar UV flux variations in the 11-y solar cycle, changing by about $1.5 \%$ from solar maximum to solar minimum.

Thus, considered separately, the factors of the QBO and the 11-y solar cycle cannot explain the observed interannual variations of ozone, because the role of each of these factors is small. In order to explain the observed anomalies of ozone it is necessary to account for possible interaction between both factors. This interaction may be a third factor and sometimes the role of this factor may be great. Following this assumption, the possibility of connection between the wintertime (January to March) variations of total ozone and the sunspot numbers at simultaneous moment in the QBO phase is investigated in the present study. This research is based on the results of Labitzke (1987), Labitzke and 
van Loon (1988, 1992, 1993), Kodera (1991，1993), Kodera et al. (1991), van Loon and Labitzke (1994), Soukharev (1997a) which were obtained by analysing a possible connection between the meteorological parameters in the winter stratosphere and the sunspot numbers when the data are grouped according to the phases of QBO. Thus, these authors have noted that during the $W$ phase of QBO there is positive correlation between the variations of temperature and geopotential heights in the winter polar stratosphere, and the solar activities. On the contrary, during the $E$ phase of $\mathrm{QBO}$, there is negative correlation. Taking into account also the known close relation between the temperature in the lower stratosphere and the total ozone (Angell, 1987, 1988; Bojkov, 1988; Kondratiyev, 1990; Shalamyansky et al., 1992; Taalas and Kyro, 1992), in the present study the connection between the ozone and the solar activity is studied with ozone data grouped according to the phases of QBO. In addition a correlation analysis between the indexes of stratospheric circulation and the sunspot numbers bearing in mind the QBO phase is also conducted. Such an analysis allows us to suggest the dynamical mechanism of the connection between ozone and solar activity.

In the present research, to obtain more objective results on possible connection between the solar cycle QBO - ozone, the analysis is conducted separately for two cases: (1) for the definition of the QBO phase at $50 \mathrm{hPa}$, and (2) for the same but at $30 \mathrm{hPa}$.

The choice of Northeastern Europe for the investigation is determined by the facts that over this region, during the winter-spring season, there is an area of climatological minimum of total ozone, and because of great probability of the formation of ozone mini-holes just over this region (Bojkov et al., 1994).

\section{Data}

In the present investigation we used the monthly means of total ozone, updated recently in the Central Aerological Observatory, Moscow and in the Main Geophysical Observatory, St.-Petersburg, Russia, derived by special techniques in months January to March between 1973-1995 on five stations in Northeastern Europe. In all of these stations filter ozonometers (M-83 and M124) are used. Detailed information about the total ozone measurements by filter ozonometers as well as about the procedure used for the calibration of the instruments is contained in the paper by Bojkov et al. (1994). Data for the following ozone measuring stations were used: Murmansk $\left(68.6^{\circ} \mathrm{N} ; 33.0^{\circ} \mathrm{E}\right)$, Pechora $\left(65.1^{\circ} \mathrm{N} ; 57.1^{\circ} \mathrm{E}\right)$, Arkhangelsk $\left(64.3^{\circ} \mathrm{N} ; 40.3^{\circ} \mathrm{E}\right)$, St.Petersburg $\left(59.6^{\circ} \mathrm{N} ; 30.2^{\circ} \mathrm{E}\right)$ and Moscow $\left(55.4^{\circ} \mathrm{N}\right.$; $\left.37.3^{\circ} \mathrm{E}\right)$. Table 1 characterizes the quantity of available monthly data of total ozone from these stations from January to March. It can be seen that the smallest amount of available data is in January where there are monthly data only from St.-Petersburg and Moscow. In February and March, there are large amounts of available data from all five stations. It should be noted

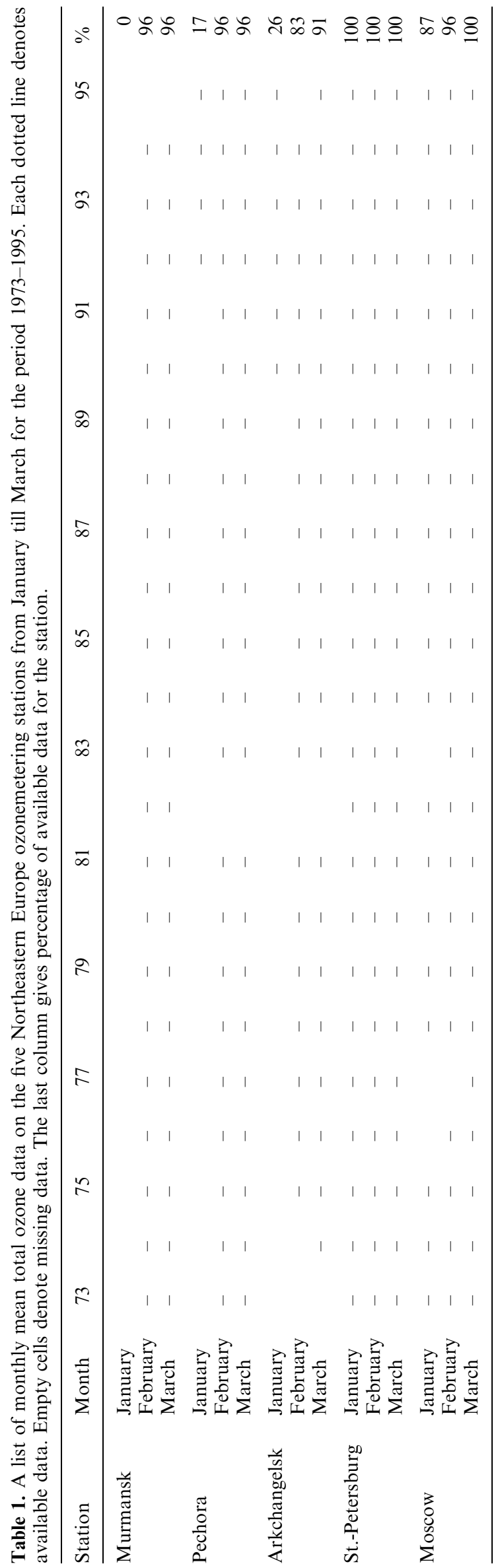


that despite the lack of observations at high-latitudinal stations in January related to difficulties in making the ground-based ozone measurements in midwinter, nevertheless because of uniformity of the ozone field inside the coldest part of circumpolar stratospheric vortex, it is possible to calculate the monthly ozone means for a whole region of Northeastern Europe just from the data for 2-3 stations. A minimum of 12 days of observation were required for the monthly ozone mean to be included in consideration.

As a rule, during the winter-early spring period the coldest part of stratospheric circumpolar vortex is situated over the region including the all studied stations. According to Shalamyansky (1987), and Shalamyansky et al. (1992), the ozone field inside this sector is uniform. From Table 2 it is clear that monthly long-term means of the total ozone for these stations are very similar. Coefficients of correlation between ozone data on the studied stations are high ( $r>0.75$ always). This fact demonstrates that total ozone for all five stations follows the same annual pattern which is typical for Northern Europe (minimum of ozone is observed in October-November, and maximum in March-April). In addition, correlation analysis between monthly anomalies (deviations from long-term 1973-1995 monthly average) of total ozone at these stations shows that the anomalies are synchronous and correlations are positive $(0.4<r<0.7)$. It is obvious that monthly anomalies of total ozone over the studied stations, are caused by atmospheric processes common over the whole region of Northeastern Europe. The uniformity of ozone field over this region allows the use of monthly ozone means for the whole region.

The long-term monthly means of total ozone for the whole Northeastern region (Table 2) were calculated by the following way. First the data from all five stations for particular months were averaged for each year (available data from stations were summarized and then divided by the number of items), allowing us to obtain the monthly ozone mean for the whole region for the given year. Then the obtained values were divided by number of years for which the monthly means for the whole region were calculated. Thus, in calculating longterm means of total ozone for the whole region the lengths of time series for each station were taken into account.

For analysis of the connection between the total ozone and the dynamics of stratospheric circulation the monthly mean index of stratospheric circulation $\left(C_{1}\right)$, offered by Wallace and Chang (1982), is used. Index $C_{1}$ represents a difference in zonal-mean geopotential height field between 40 and $70^{\circ} \mathrm{N}$ at the $30 \mathrm{hPa}$ level. It is a characteristic of the intensity of zonal circulation inside the circumpolar vortex (the more $C_{1}$, the stronger zonal transport). The use of index $C_{1}$ permits consideration of the dynamics of the winter lower stratosphere. The monthly mean indexes $C_{1}$ for the period 1958-1996 were calculated using monthly mean data of geopotential at the $30 \mathrm{hPa}$ in grid points $(10 \times 10)$ for the Northern Hemisphere. These data were received from the Stratospheric Research Group at Berlin Free University.

It should be noted that there is no standard criterion for defining the QBO phase. It is well known (Naujokat, 1986; Fedorov et al., 1994; Matveev et al., 1994) that the opposite zonal winds are often observed on the near isobaric levels of equatorial stratosphere (e.g. at 50 and $30 \mathrm{hPa}$ ). Holton and Tan (1980) took into account the QBO phase at $50 \mathrm{hPa}$. Labitzke and van Loon $(1988,1992)$ for definition of the QBO phase used the averaged zonal wind at 50 and $40 \mathrm{hPa}$. Bugaev and Kats (1971), and Ugryumov (1971) have defined the QBO phase at $30 \mathrm{hPa}$. For the results to be more objective, in the present research the QBO phases were defined separately at 30 and $50 \mathrm{hPa}$. Because of frequent changes of the zonal wind direction in midwinter, in the present work the QBO phase has been defined as the averaged zonal winds in January and February (January plus February winds divided by two). Data of zonal wind were also received from Stratospheric Research Group at Berlin Free University.

Total ozone data were given by A. M. Shalamyansky (Main Geophysical Observatory, St.-Petersburg, Russia), who is responsible for the Russian ground-based

Table 2. Long-term (1973-1995) monthly means of total ozone (in Dobson units) for the five Northeastern Europe stations from January to March. Besides the long-term means, for the each station the following information is added: the number of years of data which are used to calculate the means, and the standard deviation (sigma) of total ozone for the given month and station

\begin{tabular}{|c|c|c|c|c|c|c|}
\hline Statistics & Murmansk & Pechora & Arkchangelsk & St.-Petersburg & Moscow & Whole region \\
\hline \multicolumn{7}{|c|}{ JANUARY } \\
\hline Mean & - & 323 & 303 & 348 & 343 & 345 \\
\hline Years & - & 4 & 6 & 23 & 20 & 23 \\
\hline Sigma & - & 49 & 31 & 31 & 26 & 28 \\
\hline \multicolumn{7}{|c|}{ FEBRUARY } \\
\hline Mean & 395 & 379 & 382 & 377 & 374 & 382 \\
\hline Years & 22 & 22 & 19 & 23 & 22 & 23 \\
\hline Sigma & 55 & 45 & 46 & 37 & 27 & 34 \\
\hline \multicolumn{7}{|l|}{ MARCH } \\
\hline Mean & 402 & 388 & 394 & 389 & 391 & 393 \\
\hline Years & 22 & 22 & 21 & 23 & 23 & 23 \\
\hline Sigma & 41 & 42 & 36 & 28 & 28 & 30 \\
\hline
\end{tabular}


ozone network. Data for January sunspot numbers means were received from the Solar Geophysical Data published by Joint NOAA-USAF Space Weather Operations.

3 Running correlations between the total ozone over Northeastern Europe and the equatorial zonal wind

In the recent paper by Soukharev (1997b), where the same ozone data as in this study were used, it was shown that there is a linear correlation between the monthly anomalies of total ozone over Northwestern Russia in wintertime and the sunspot numbers when ozone data are grouped according to the QBO phases. During the $W$ phases of QBO, positive correlations and during the $E$ phases of QBO negative correlations are observed. For February, and partially, for March the results are statistically significant (with $5 \%$ level of significance). During the $W$ phases the coefficients of correlation for these months are $r=0.63$ and $r=0.57$ respectively. During the $E$ phases the coefficients are $r=-0.89$ and $r=-0.49$ respectively. It should be noted that these
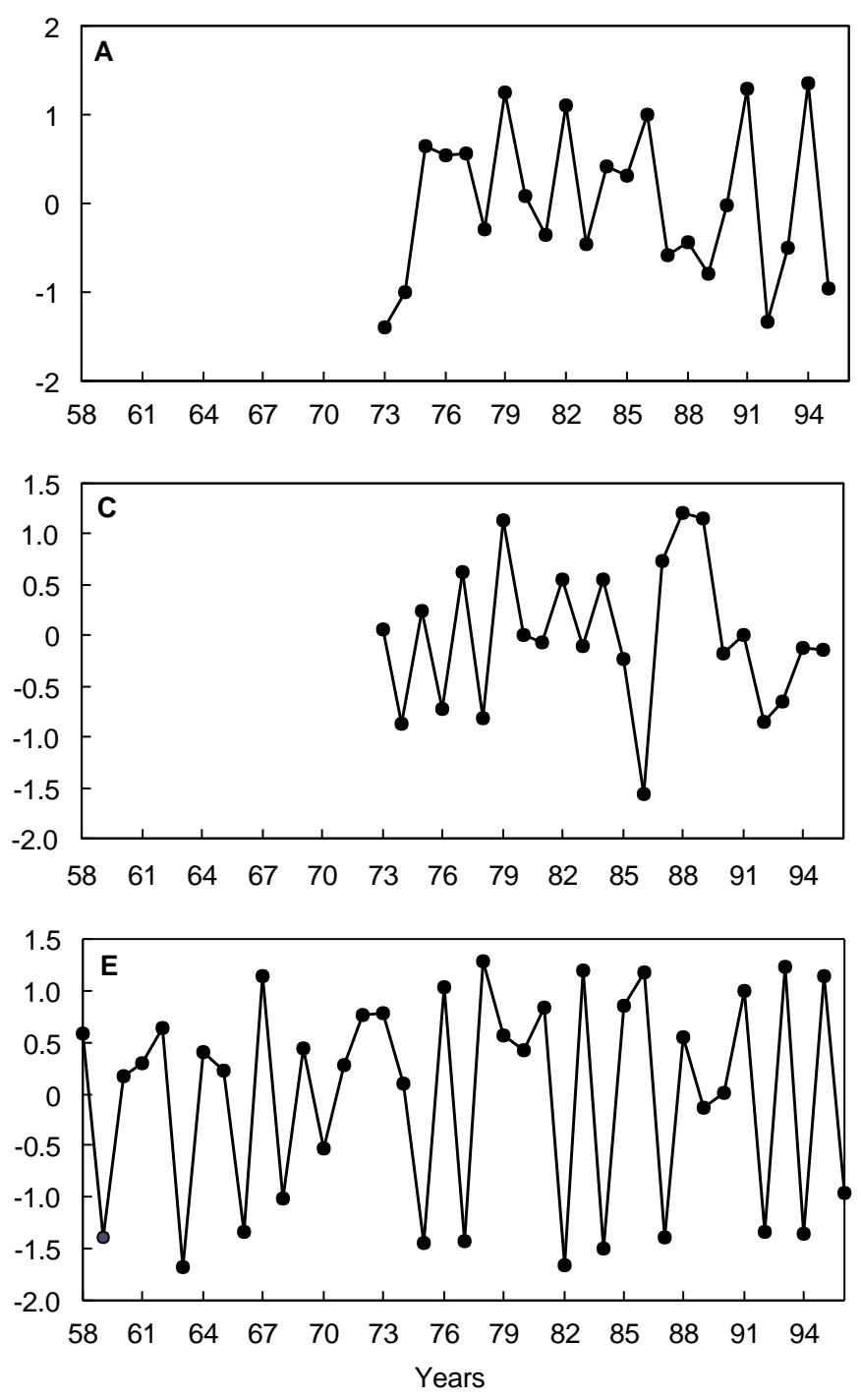

results were obtained with the QBO phases defined according to Labitzke's known catalogue of QBO phases (where the equatorial zonal wind is defined as the averaged wind at 50 and $40 \mathrm{hPa}$ ). However, it is known that some authors (e.g. Teitelbaum and Bauer, 1990; Salby and Shea, 1991) doubted the statistical reliability of connections between the atmospheric parameters and the solar activity at the account of the QBO phase. In the present research to reveal the connections between the ozone and the solar activity, two methods are used: (1) method of running correlations between the ozone and the equatorial zonal wind; (2) linear correlation between the ozone and the sunspot numbers at $W$ and $E$ phases of QBO (at the definition of phase at 50 and $30 \mathrm{hPa}$ ). The running correlation method was recently used by Kodera (1993) to illustrate the quasi-decadal modulation of the QBO influence on polar stratospheric temperatures. In this work, this method is used to show how this modulation of the QBO affects ozone over Northeastern Europe.

Figure 1 shows the January, February and March mean total ozone $(X)$ (Fig. 1a,b,c) and the JanuaryFebruary mean equatorial zonal wind $(U)$ at 50 and
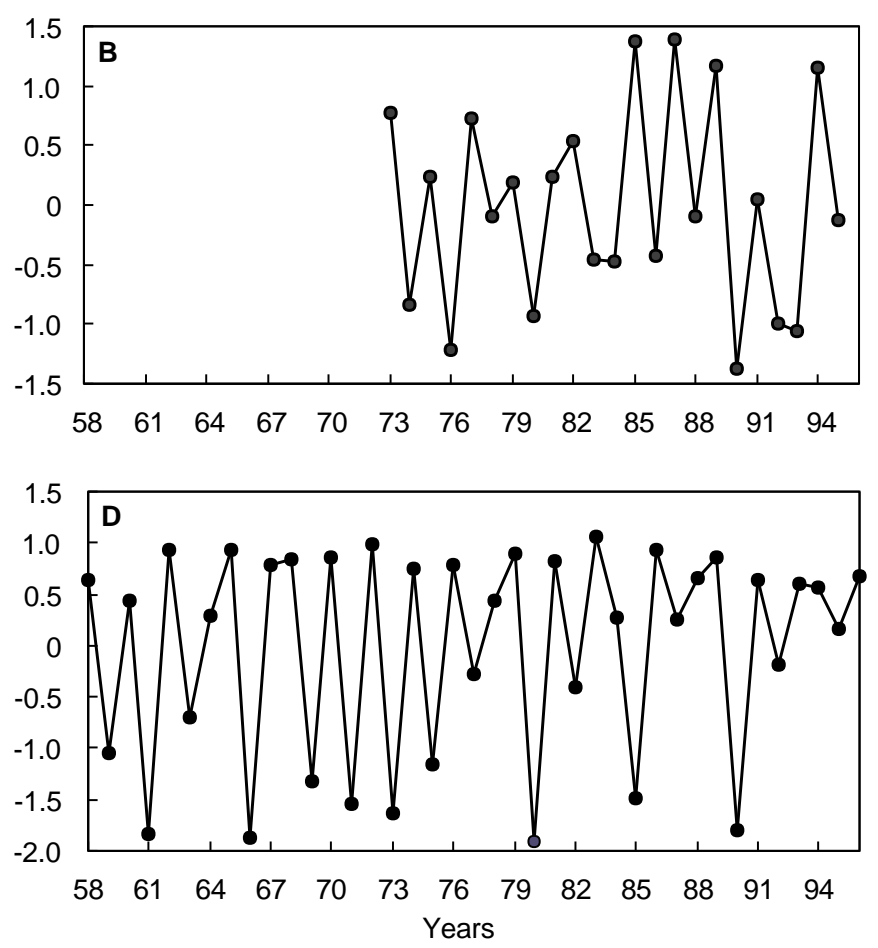

Fig. 1a-e. Time series of the a January b February and $\mathbf{c}$ March means of total ozone (in Dobson units) over Northeastern Europe between 1973-1995, and the January-February mean equatorial zonal wind at $\mathbf{d} 50 \mathrm{hPa}$ and e $30 \mathrm{hPa}$ for 1958-1996. All time series have been normalized (the long-term mean subtracted and then divided by the standard deviation). The negative linear trends from ozone time-series have been subtracted 
$30 \mathrm{hPa}$ (Fig. 1d,e). According to Kodera (1993), a change in the relationship between $X$ and $U$ is investigated by calculating the running correlation $r$ for year $i$ as follows:

$$
r_{i}=\frac{\frac{1}{M} \sum_{n=i-m}^{i+m} X_{n}^{\prime} U_{n}^{\prime}}{\left(\frac{1}{M} \sum_{n=i-m}^{i+m} X_{n}^{\prime} X_{n}^{\prime} \frac{1}{M} \sum_{n=i-m}^{i+m} U_{n}^{\prime} U_{n}^{\prime}\right)^{\frac{1}{2}}},
$$

where $M=2 m+1$ is the window width and dashed quantities are deviations from $M$ year mean as

$X_{i}^{\prime}=X_{i}-\frac{1}{M} \sum_{n=i-m}^{i+m} X_{n}$

The running correlations between the zonal wind and the total ozone for January do not show a clear 11-y signal. However the running correlations between the equatorial zonal wind at $50 \mathrm{hPa}$ and $30 \mathrm{hPa}$, and the total ozone for February and March respectively (Fig. 2a,b,c,d) demonstrate that there is excellent correspondence between the February variations in $r$ (when
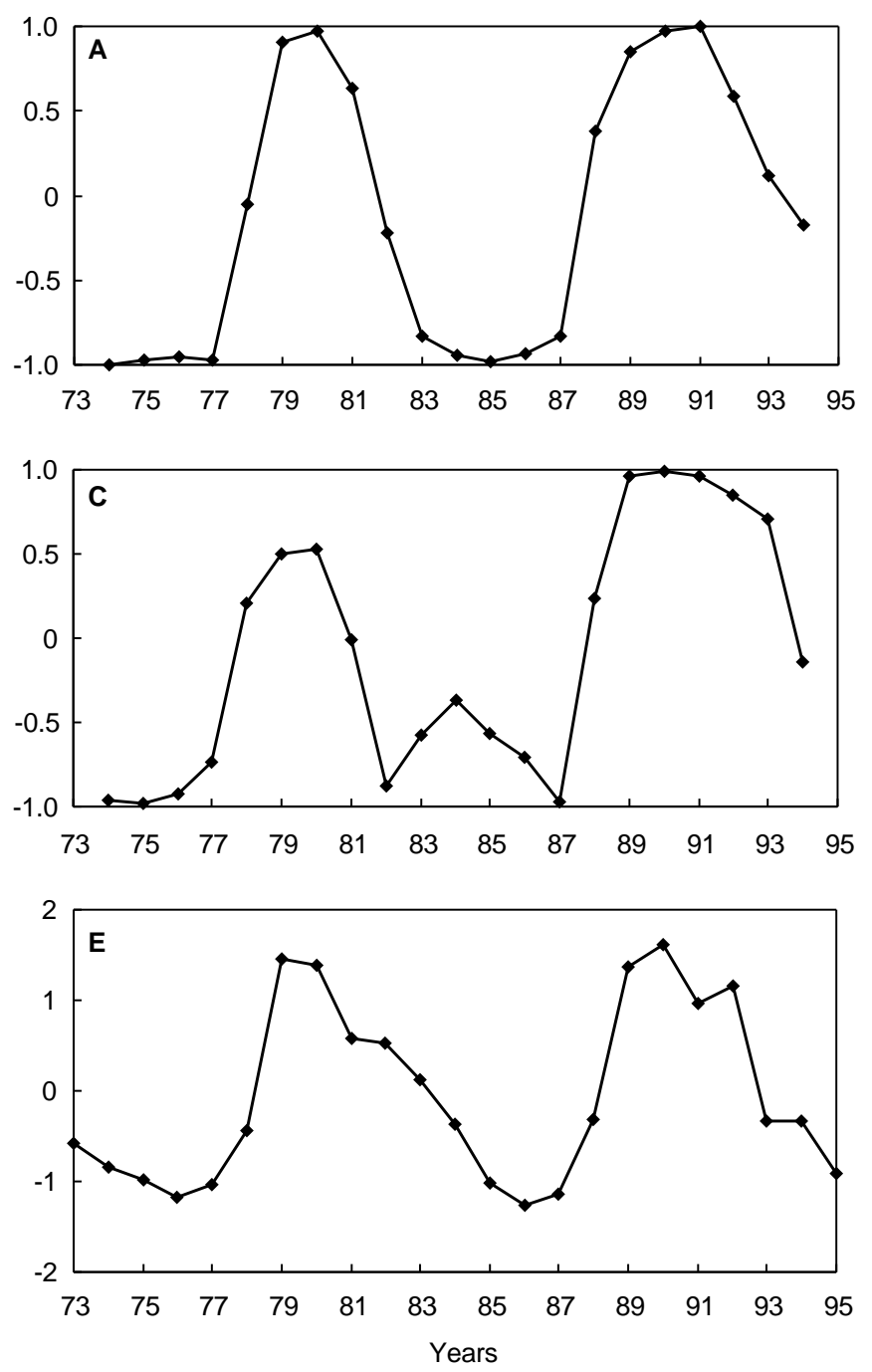

the zonal wind is defined at $50 \mathrm{hPa}$ ) and the 11-y solar cycle. The correspondence is also good in March, especially when zonal wind is defined at $50 \mathrm{hPa}$.

A visual comparison of the Fig. 2a, 2b and Fig. 2c, $2 \mathrm{~d}$ reveals that using the $50 \mathrm{hPa}$ level for the definition of the zonal wind, the correspondence between the variations of coefficient of running correlations and the sunspot numbers is much clearer than using the $30 \mathrm{hPa}$ level. This fact is in accordance with well-known vertical distribution of ozone: most of the ozone is found in the lower stratosphere. On Fig. 2 the running correlations are calculated for window width of $M=3$. The experiments which have been made in the present investigation, showed that the changes in window width do not affect the results, apart from the fact that the amplitude of obtained 11-y solar signal is larger for $M=3$ than for $M=5$.

In this analysis, the clear 11-y signals in February and March were obtained without any suitable grouping of ozone data according to the QBO phases. This fact shows that there is close connection between the interannual variations of ozone over North-eastern Europe in February and March and the solar cycle with reference to the QBO phase.
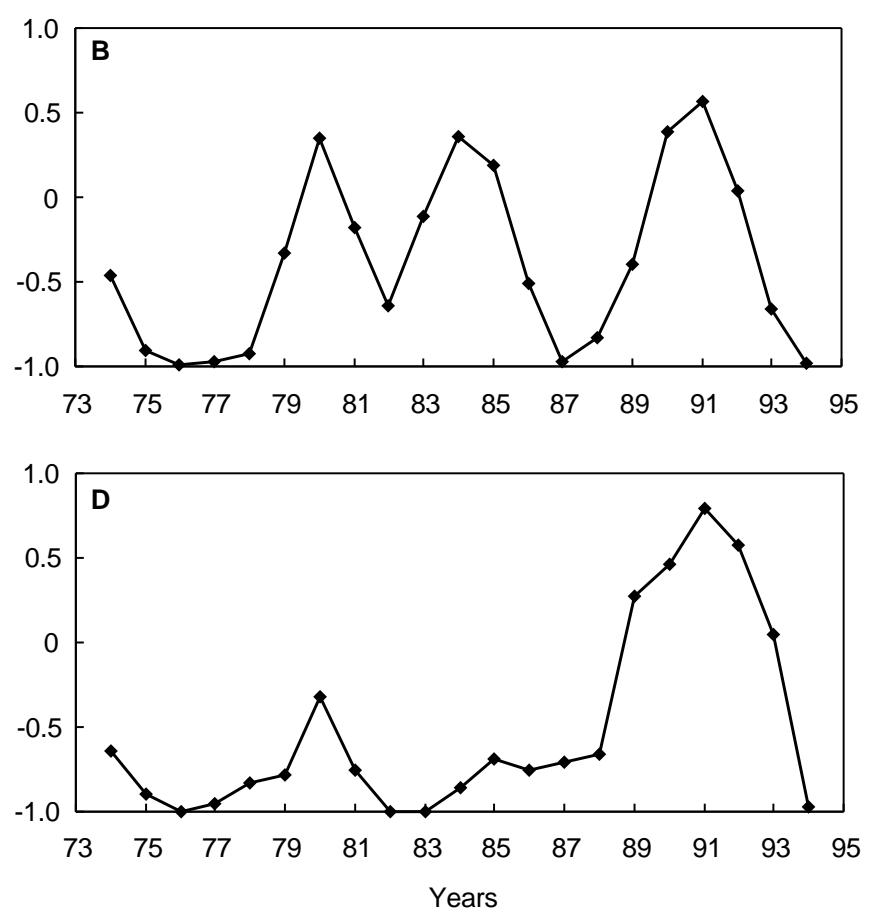

Fig. 2a-e. Time series of the running correlations between the $\mathbf{a}, \mathbf{b}$ February and $\mathbf{c}, \mathbf{d}$ March means of total ozone over Northeastern Europe and the equatorial zonal winds at $50 \mathrm{hPa}$ and $30 \mathrm{hPa}$ respectively. Running correlations are calculated using 3-year window width. e is time series of January mean sunspot numbers. All time series have been normalized (procedure in Fig. 1 caption) 


\section{Connection between the dynamics of stratospheric circulation and the solar activity}

At the present time it is difficult to explain physically, how the transition from solar minimum to solar maximum can change the sign of the influence of the QBO on the geopotential, temperature and ozone fields. Nevertheless, it is clear that the influence of the solar activity cannot be direct, and probably, it occurs as a result of changes in atmospheric circulation. If this is true, then the indexes of stratospheric circulation should reflect this influence. Table 3 shows the coefficients of linear correlation between the total ozone monthly means over North-eastern Europe and the sunspot numbers as well as between the monthly mean indexes of stratospheric circulation $C_{1}$ and the sunspot numbers. It should be noted that before this analysis the statistically significant negative linear ozone trends were subtracted from initial time series (trends were determined used the standard least squares method). As can be seen from Table 3 , there is a positive correlation between the wintertime ozone variations and the January mean sunspot numbers during the $W$ phase of $\mathrm{QBO}$, and a negative correlation during the $E$ phase of QBO. Correlation coefficients for February are most statistically significant (5\% significance level) during the $E$ phase where the QBO phase is defined at $50 \mathrm{hPa}$ $(r=-0.89)$. For March the coefficients are less, but are significant during the $W$ phase of QBO $(r=0.57$ and $r=0.53$ when the QBO phase is defined at 50 and $30 \mathrm{hPa}$ respectively). In Table 3 the 5\% levels of significance for the correlation coefficients were calculated using the $(Z)$ method presented by R. Fisher (Panofsky and Brier, 1972). Table 3 shows also that there is negative correlation between the indexes $C_{1}$ and the sunspot numbers during the $W$ phases and positive correlation during the $E$ phases of QBO. The maximal and statistically significant coefficients are for February. It is interesting that, in the same way as the correlation between the ozone and the solar activity, the correlation between the indexes $C_{1}$ and the sunspot numbers is also revealed better when the $\mathrm{QBO}$ phases is defined at $50 \mathrm{hPa}$ rather than at $30 \mathrm{hPa}$.
In order to demonstrate connection between stratospheric dynamics and solar activity the running correlations method, described already was used again. In a similar way to the running correlations between the total ozone over Northeastern Europe and the equatorial zonal wind, the running correlations between the index $C_{1}$ and the zonal wind were calculated separately for two cases: i.e., for the QBO phase at 50 and $30 \mathrm{hPa}$, respectively. Running correlations for January did not show an 11-y solar signal. However, Fig. 3 shows that there is a good correspondence between the running correlations for February and March, and the sunspot numbers. The best correspondence is observed in February. It is easy to see that the running correlations on Fig. 3 are the same as those on Fig. 2 but only in the reverse sense: the running correlations between the ozone and the zonal wind are in phase with the 11-y solar cycle, but the running correlations between the index $C_{1}$ and the zonal wind are in the directly opposite phase with it.

A visual comparison of Figs. 2 and 3 reveals that using the zonal wind at $50 \mathrm{hPa}$, the correspondence between the running correlations and the sunspot numbers is clearer than using the zonal wind at $30 \mathrm{hPa}$. An exception is observed for running correlations between $C_{1}$ and sunspot numbers in March, when the use of the zonal wind at $30 \mathrm{hPa}$ gives better correspondence.

\section{Discussion}

Both the running correlations and linear correlation methods confirm the assumption that the joint effect of the QBO and of the 11-y solar cycle may be an important factor which influences the interannual variations of total ozone over Northeastern Europe in later winter - early spring through the changes in stratospheric circulation. The joint effect may be a major factor, causing the interannual February variations of total ozone. If the relation solar cycle - QBO - ozone occurs through stratospheric circulation, a connection between the variations of total ozone and index $C_{1}$

Table 3. Coefficients of linear correlation between the monthly means of total ozone over Northeastern Europe and the sunspot numbers, as well as between the monthly mean indexes $C_{1}$ and the sunspot numbers, during the different QBO phases defined separately at 50 and $30 \mathrm{hPa}$. For the analyses the monthly ozone means for 1973-1995 with subtracted linear trend for this period and monthly means of index $C_{1}$ for 1958-1996 were used. In the first case, total ozone data used for the correlation analysis, were 15 for westerly and 8 for easterly phases of QBO. In the second case, the used data for $C_{1}$, were 25 for westerly and 14 for easterly phases of QBO

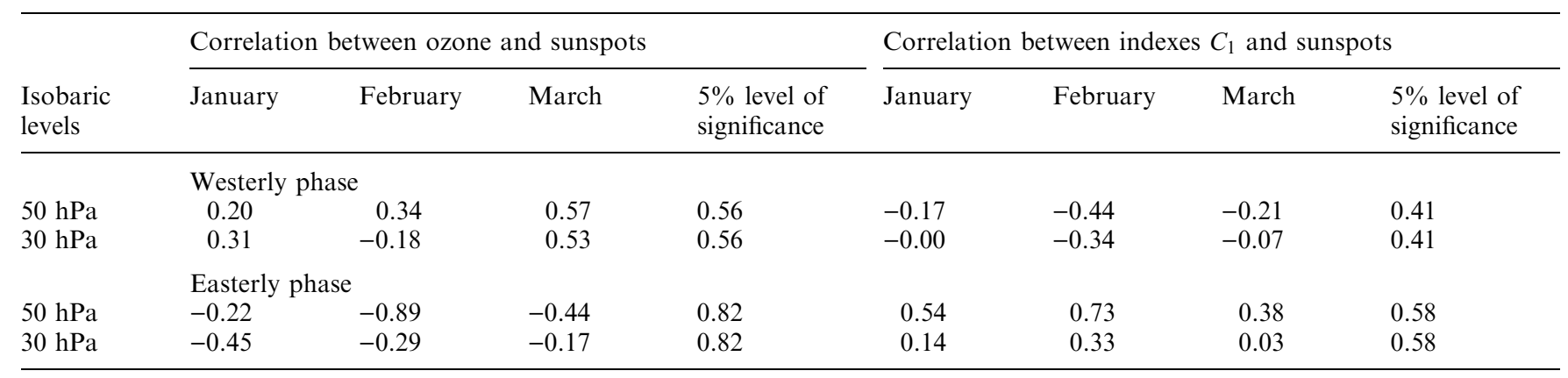



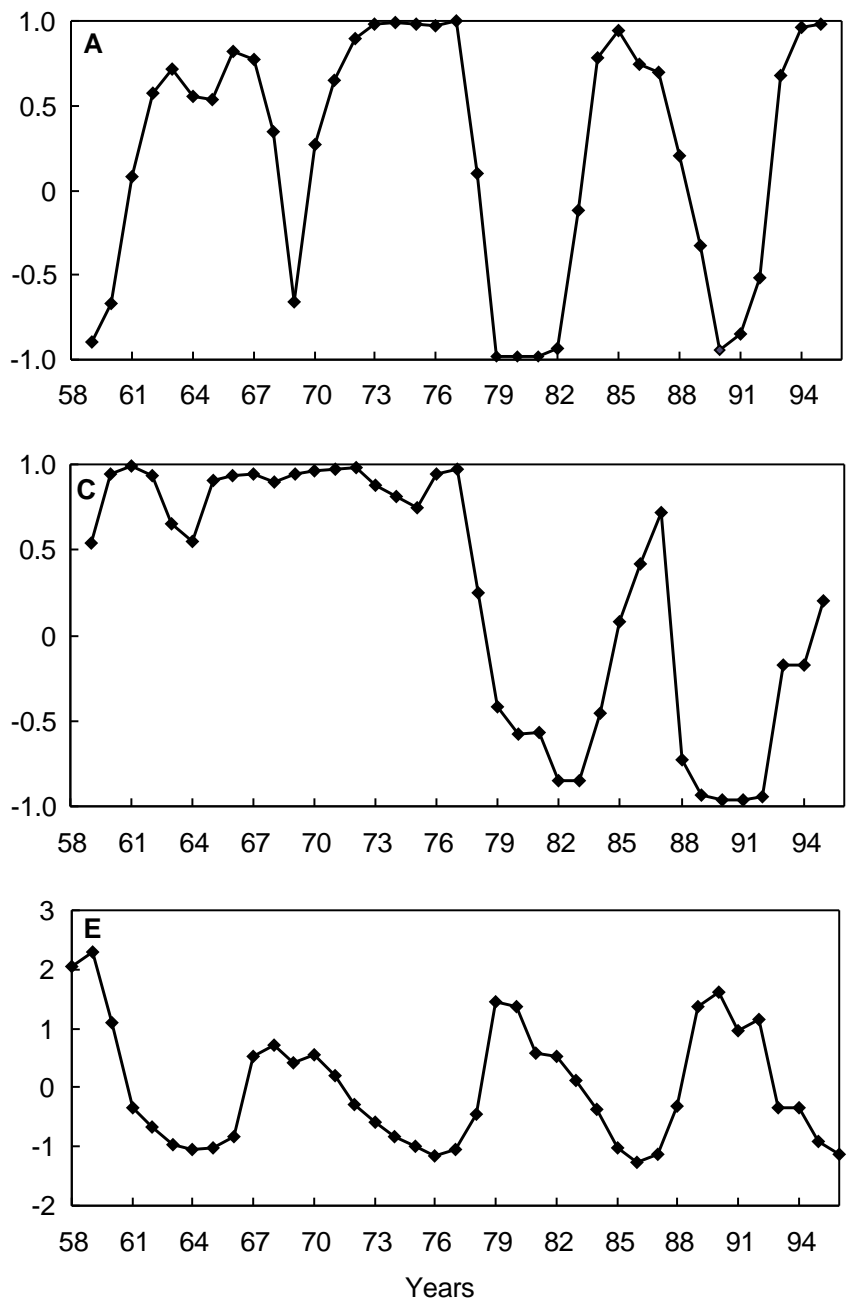

should exist. The calculated correlation coefficients between the ozone over Northeastern Europe, and the index $C_{1}$, have showed that despite the fact that the index $C_{1}$ is global (on hemispheric scale) and ozone variations are considered over small region the connection between these parameters is reasonably close: the correlation coefficients are $r=-0.28 ; \quad r=-0.58$; $r=-0.40$ for January, February and March respectively. The largest and statistically significant (5\% level of significance) coefficient is for February. The connection between changes of ozone and stratospheric dynamics has a clear physical explanation: a weakening of zonal flow in the lower stratosphere leads to the intensification of ozone transport from low to high latitudes, and therefore, to an increase of polar ozone.

Why do the running correlations between the variations of ozone and index $C_{1}$ from one side, and the equatorial zonal winds from other side, demonstrate the best modulation of 11-y solar signal just for February? And why the connections between the interannual changes of ozone over Northeastern Europe and the index $C_{1}$ are closest just for February too? Probably, the reason is that in February the intensity of meridional circulation is the highest. According to the recent research of Pawson et al. (1995), "although temperature
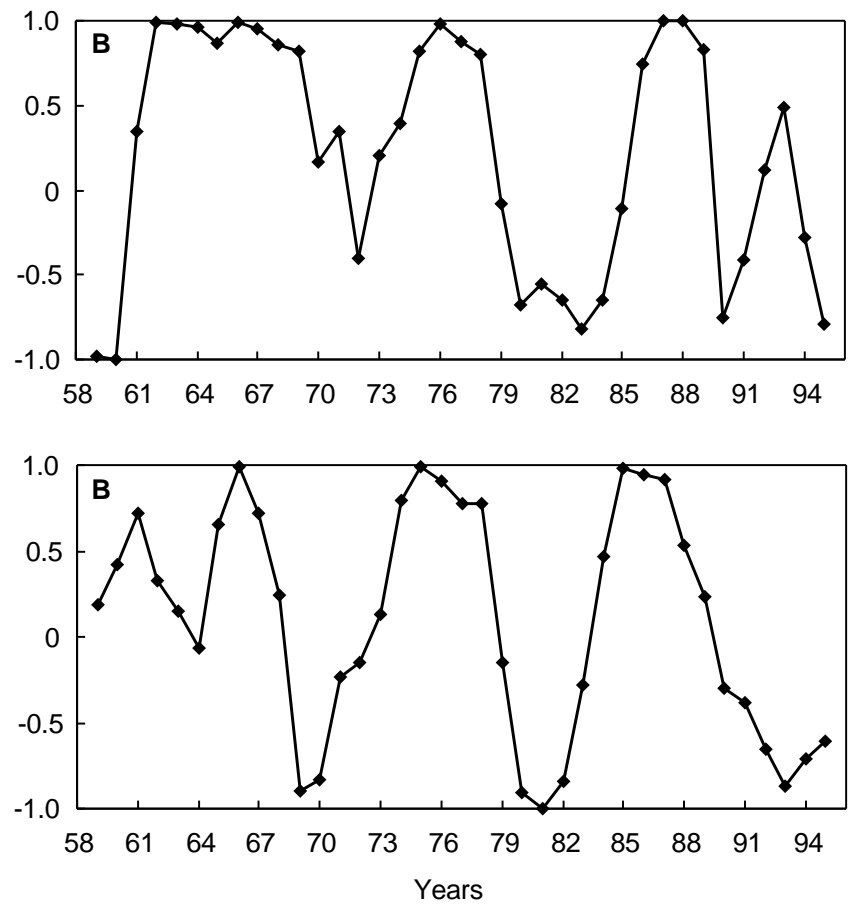

Fig. 3a-e. Time series of the running correlations between the $\mathbf{a}, \mathbf{b}$ February and $\mathbf{c}, \mathbf{d}$ March means of index $C_{1}$ and the equatorial zonal winds at $50 \mathrm{hPa}$ and $30 \mathrm{hPa}$ respectively. Running correlations are calculated using 3-year window width. e shows the timeseries of the January mean sunspot numbers. All time series have been normalized (see Fig. 1)

less than $192 K$ occurs most often in January, the stratosphere may be colder in February, when the $185 \mathrm{~K}$ contour encloses a region extending over Europe, which is larger than the small regions near the Pole, which it covers in January". In addition Kane (1992) noted that most major winter stratospheric warmings are observed just in February.

An approximate scheme showing the association between the solar cycle (considering the QBO phase) and the ozone over the studied region may be the following. The solar cycle during a certain phase of the QBO causes correspondent changes in stratospheric circulation (Fig. 3). Stratospheric dynamics are most closely related to the solar cycle in February (Table 3). As the correlations between the indexes of stratospheric circulation and the variations of ozone are greatest in February, the closest correlations between the ozone and the solar activity are observed also in February (Fig. 2 and Table 3).

It is obvious that the results obtained in the present study need a physical explanation of the relation between solar activity and stratospheric circulation. In spite of some attempts (e.g., Kodera, 1991) to explain this relation, the real mechanism of this relation continues to be unclear and awaits further investiga- 
tions. Nevertheless, based on the close connection found between the interannual variations of ozone in February and the solar activity during the certain QBO phase, it is possible to predict the sign of monthly anomaly of total ozone in February over Northeastern Europe.

Acknowledgements. The author would like to thank I. K. Adamenko (Makarov Naval Academy, St.-Petersburg, Russia), O. A. Drozdov (St.-Petersburg State University, Russia) and two unknown references for useful discussions of results, as well as K. Labitzke, B. Naujokat (both from Free University Berlin, Germany) and A. M. Shalamyansky (Main Geophysical Observatory, St.-Petersburg, Russia) for the necessary materials for the investigation. The author is also very grateful to N. Sinor, M. Stake and V. Rogojkin for the support in preparation of this manuscript.

The Editor in chief thanks J. Staehelin and I. L. Karol for their help in evaluating this paper.

\section{References}

Aleksandrov, E. L., Y. A. Izrael, I. L. Karol, and A. K. Khrgian, Ozone shield of the Earth and its changes, St.-Petersburg, Gidrometeoizdat, 287 p. (in Russian), 1992.

Angell, J. K., Seasonal differences in the trend of total ozone and contributions from tropospheric and stratospheric layers, Mon. Weather. Rev., 115, 753-762, 1987.

Angell, J. K., Relation of Antarctic $100 \mathrm{mb}$ temperature and total ozone to equatorial QBO. equatorial SST, and sunspot number, 1958-87. Geophys. Res. Lett., 15, 915-918, 1988.

Bekorukov, V. I., V. N. Glazkov, and A. A. Kukoleva, Empirical model of total ozone for Northern hemisphere at the different phases of quasi-biennial circle, Meteorol. Gidrol. 2, 36-40 (in Russian), 1994

Bojkov, R. D., Ozone variations in the Northern polar region, Meteorol. Atmos. Phys., 38, 117-130, 1988.

Bojkov, R. D., V. E. Fioletov, and A. M. Shalamyansky, Total ozone changes over Eurasia since 1973 based on reevaluated filter ozonometer data, J. Geophys. Res., 99, 22985-22999, 1994.

Bugaev, V. A., and A. L. Kats, Quasi-biennial recurrence and evolution of circulation and weather in Atlantic Eurasian sector of hemisphere in 1968-1970 years, in: Quasi-biennial recurrence and circulation in atmosphere and ocean, Leningrad, Gidrometeoizdat (in Russian), 1971.

Chandra, S., and R. D. McPeters, The solar cycle variation of ozone in the stratosphere inferred from Nimbus 7 and NOAA 11 satellites, J. Geophys. Res., 99, 20665-20671, 1994.

Dunkerton, T. J., and M. P. Baldwin, Quasi-biennial modulation of planetary wave fluxes in the northern hemisphere winter, J. Atmos. Sci., 48, 1043-1061, 1991.

Fedorov, V. V., V. N. Glazkov, I. V. Bugaeva, and D. A. Tarasenko, About connection of quasi-biennial oscillations of equatorial stratospheric circulation with variations of atmospheric parameters, Meteorol. Gidrol. 10, 24-30 (in Russian), 1994.

Holton, J. R., The quasi-biennial oscillations in the Earth's atmosphere and it's link to longer period variability, NATO ASI Series. I 25, 1994.

Holton, J. R., and J. Austin, The influence of the equatorial QBO on sudden statospheric warmings, J. Atmos. Sci., 48, 4, 1991.

Holton, J. R., and H. C. Tan, The influence of the equatorial QBO in the global circulation at 50mb, J. Atmos. Sci., 37, 2200-2208, 1980.

Holton, J. R., and H. C. Tan, The quasi-biennial oscillation in the Northern Hemisphere lower stratosphere, J. Meteorol. Soc., 60, 140-148, 1982.

Kane, R. P., Long-term variation of stratospheric temperature at the North Pole, J. Atmos. Terr. Phys., 54, 1139-1148, 1992.
Karol, I. L., L. P. Klyagina, and A. M. Shalamyansky, Evaluations of seasonal trends of total ozone in a main air masses of Northern Hemisphere in 1975-86 (21 cycle of solar activity), in: Investigation of atmospheric ozone (Ozone-90), Moskva, Gidrometeoizdat, (in Russian), 1992.

Khrgian, A. K., About processes of long-term and short-term changes of ozone in some regions of Northern hemisphere, Meteorol Gidrol., 7, 5-16, (in Russian), 1992.

Kodera, K., The solar and equatorial QBO influences on the stratospheric circulation during the early Northern Hemisphere winter, Geophys. Res. Lett., 18, 1023-1026, 1991.

Kodera, K., Quasi-decadal modulation of the influence of the equatorial Quasi-Biennial Oscillation on the north polar stratospheric temperatures, J. Geophys. Res., 98, 7245-7250, 1993.

Kodera, K., M. Chiba, and K. Shibata, A general circulation model study of the solar and QBO modulation of the stratospheric circulation during the Northern Hemisphere winter, Geophys. Res. Lett., 18, 1209-1212, 1991.

Kondratiyev, K. Y., Global dynamics of ozone, in Trudy VINITI, Geomagnetizm and high layers of atmosphere. vol. 11, Moskva, p. 210, (in Russian), 1990.

Labitzke, K., On the interannual variability of the middle stratosphere during northern winters. J. Meteorol. Soc., Japan, 60, 124-139, 1982.

Labitzke, K., Sunspots, the QBO, and the stratospheric temperature in the north polar region, Geophys. Res. Lett., 14, 535-537, 1987.

Labitzke, K., and H. van Loon, Associations between the 11-year solar cycle and the atmosphere, Part 1: the troposphere and stratosphere in the Northern Hemisphere in winter, J. Atmos. Terr. Phys., 50, 197-206, 1988.

Labitzke, K., and H. van Loon, On the association between the QBO and the extratropical stratosphere, J. Atmos. Terr. Phys., 54, 1453-1463, 1992.

Labitzke, K., and H. van Loon, Some recent studies of probable connections between solar and atmospheric variability, Ann. Geophysicae, 11, 1084-1094, 1993.

Matveev, L. T., Ye. L. Matveev, and S. A. Soldatenko, The qualitative analysis of occurrence of synoptical vortexes in atmosphere, Meteorol. Gidrol,. 8, 5-17, (in Russian), 1994.

Naujokat, B., An update of the observed quasi-biennial oscillation of the stratospheric winds over the tropics, J. Atmos. Sci., 43, 1873-1877, 1986

Panofsky, H. A., and G. W. Brier, Some applications of statistics to meteorology, Leningrad, Gidrometeoizdat, 1972, 209 pp. (in Russian).

Pawson, S., K. Labitzke, R. Lenschow, B. Naujokat, B. Rajewski, M. Wiesner, and R.-C. Wohlfart, Climatology of the Northern Hemisphere stratosphere derived from Berlin analyses, Part 1: Monthly means, Meteorol. Abhand., Band 7/Heft 3, 1993.

Pawson, S., B. Naujokat, and K. Labitzke, On the polar stratospheric cloud formation potential of the northern stratosphere, J. Geophys. Res., 100, 23,215-23,225, 1995.

Salby, M. L., and D. Shea, Correlations between solar activity and the atmosphere: an unphysical explanation, J. Geophys. Res., 96, 22,579-22,595, 1991 .

Shalamyansky, A. M., Spatial-time structure of ozone field in borders of air masses, in: Atmospheric ozone. Trudy 6 Vsesojuznogo simposiuma, Leningrad, 15-17 May 1985, 230237, (in Russian), 1987.

Shalamyansky, A. M., A. V. Mironov, N. B. Volkova, and N. D. Ionina, Formation of regions with external values of ozone in high latitudes of Northern Hemisphere, in: Investigation of atmospheric ozone (Ozone-90). Moskva, Gidromateoizdat, 34 45, (in Russian), 1992.

Soukharev, B. E., The interannual variability of temperature in the polar stratosphere during the winter: the influence of the QBO phase and an 11-year solar cycle, J. Atmos. Solar-Terr. Phys., 59, 469-477, 1997a. 
Soukharev, B. E., About connection of anomalies of ozone over North-Western region of Russia in winter period with quasibiennial cycle of equatorial stratosphere and solar activity, Meteorol. Gidrol., 8, 74-84, 1997b (in Russian).

Stolarski, R. S., P. Bloomfield, R. D. McPeters, and J. R. Herman, Total ozone trends deduced from Nimbus 7 TOMS data, Geophys. Res. Lett., 18, 1015-1018, 1991.

Taalas, P., and E. Kyro, The stratospheric winter of 1991/92 at Sodankyla in the European Arctic as compared with 1965-92 meteorological and 1988-91 ozone sounding statistics, Geophys. Res. Lett., 21, 1207-1210, 1992.

Tarasenko, D. A., Structure and circulation of Northern Hemisphere stratosphere and mesosphere, Gidrometeoizdat, Leningrad, (in Russian), 1988.
Teitelbaum, H., and P. Bauer, Stratospheric temperature eleven year variations: solar cycle or stroboscopic effect? Ann. Geophysicae, 8, 239-242, 1990.

Ugryumov, A. I., Quasi-biennial recurrence of spring-summer circulation of atmosphere, Trudy Gidrometcent SSSR, 77, 1727 (in Russian), 1971.

van Loon, H., and K. Labitzke, The 10-12-year atmospheric oscillation, Meteorol. Z 3, 259-266, 1994.

Wallace, J. M., and F.-C. Chang, Interannual variability of the wintertime polar vortex in the northern hemisphere middle stratosphere, J. Meteorol. Soc. Japan, 60, 149-155, 1982.

WMO Scientific Assessment of 1994, Rep., 37, Ozone depletion, 1994. 